\title{
EDITORIAL
}

\section{La investigación científica, ideología causal en ciencias de la salud}

\section{Martha Bernal-García}

Profesora titular, Programa de Medicina, Facultad de Ciencias de la Salud Universidad de Boyacá, Tunja, Colombia

La Organización Mundial de la Salud (OMS) considera la investigación en salud como el proceso de obtención metódica de conocimientos y tecnologías digitales en pro del mejoramiento de la salud, que tiene relevancia vital para el desarrollo económico y la seguridad sanitaria mundial (1). Siendo en ese sentido concebida la investigación con la visión global relacionada directamente con la salud de los seres humanos que, sin duda, se viene afianzando en el último decenio, tanto estratégica como sinérgicamente, hacia su política sólida de cobertura y sostenibilidad, generando, también, un creciente interés a nivel mundial, con la participación de variados y numerosos sectores, alianzas público-privadas y disciplinas.

La tradición científica ha ocupado y privilegiado a las ciencias de la salud, para el estudio de los problemas de la salud, que integran en su seno un reto cotidiano, constituyéndose en un deber de quienes trabajan en el área de la salud, en la cual la práctica investigativa científica básica y aplicada debe ser de calidad. ¿Cómo se establece tal diferencia? Si no hay claridad perceptible en lo que es y debe ser el referente que representa investigar, más bien es desemejante tanto para quienes se están formando como para quienes son profesionales en ciencias de la salud, pese a que día a día se estime la resolución de problemas con orientación clínica y la racionalidad del diagnóstico, sin más ni menos desde la aplicación del llamado "método científico" que viene de mucho tiempo atrás, tal como se requieren los conocimientos previos y las hipótesis para demostrar algo. ¿Es que acaso el mero hecho de la práctica le proporciona un conocimiento científico?; entonces, ¿cuál sería su lugar en la investigación? El propio sentido tomará perspectivas personales y metodológicas, pero ¿serán científicas?

La investigación científica se inicia, realmente, cuando "el acervo de conocimiento disponible es insuficiente para manejar determinados problemas" (2). Esto hace necesario estructurar un cuerpo de conocimiento científico, en el cual el rigor es indispensable; no bastan numerosos procesamientos y pruebas estadísticas, meramente técnicos y a veces de adusto significado, que robustecen las publicaciones de 
investigaciones sin la esencia de lo científico, generando conflicto con el objetivo y las características de la investigación científica que, para el caso de las ciencias de la salud, constituye un cimiento importante del progreso. Por ello, es fundamental diferenciar entre el problema de investigación, en el que preexiste la ciencia para responderlo, y puede ser admitido, válido y útil para algo o alguien, y el problema de investigación científica, que se basa en buscar respuestas a lo que la ciencia no ha resuelto y, en consecuencia, necesita de los propios métodos imprescindibles de la ciencia, como lo es el método científico.

Al respecto, vale la pena, retomar e interiorizar varios de los conceptos relacionados, que Mario Bunge escribe notoriamente; a continuación, algunos extractos de diferentes apartados de su libro titulado 'La ciencia, su método y su filosofía':

"[...] La ciencia es explicativa: intenta explicar los hechos en términos de leyes, y las leyes en términos de principios. La ciencia es abierta: no reconoce barreras a priori que limiten el conocimiento. La ciencia es útil: porque busca la verdad. La ciencia es eficaz en la provisión de herramientas para el bien y para el mal $[\ldots] "$.

Sin embargo, no toda la investigación científica procura el conocimiento objetivo, pero gestiona el conocimiento científico,

"[...] que es fáctico: parte de los hechos, los respeta hasta cierto punto y siempre vuelve a ellos; trascien de los hechos: descarta los hechos, produce nuevos hechos, y los explica; es claro y preciso: sus problemas son distintos, sus resultados son claros; es comunicable: no es inefable sino expresable, no es privado sino público; es verificable: debe aprobar el examen de la experiencia [...]" (3).

La evaluación de lo que se genera como conocimiento científico, desde la investigación científica y las diversas actividades científicas inmersas, ha producido y revolucionado varios indicadores cienciométricos, bibliométricos, infométricos, webmétricos y otros observadores cuantificables como políticas científicas y, con ese fin, es cuestionable. ¿De dónde viene tanta información?, ¿son, acaso, diferenciadas la producción académica y la científica?, ¿se diversifican esos indicadores con las metas desde esas políticas?, ¿cómo han evolucionado estas métricas en la producción de ciencias de la salud a nivel internacional? Estos y otros interrogantes son generados por tangibles cambios científico-tecnológicos, en los cuales el privilegio de las ciencias de la salud se transforma en competencia, a cuenta de su productividad. 
Se evidencian distintas perspectivas epistemológicas sobre lo que es y no es la investigación científica en las ciencias de la salud, la formación y el rol de quienes investigan en el área, y sus implicaciones en la significatividad de las comunidades científicas. iEl tema es serio y su ideología compromete la conciencia y los retos de muchos! Lo causal está de manera axiomática para las ciencias de la salud, ¿se diferencia, orienta y desarrolla adecuadamente?, ¿merece comparación el desarrollo de las habilidades clínicas con las científicas para su labor asistencial y social?

\section{REFERENCIAS}

1. Organización Mundial de la Salud. 63. ${ }^{\text {a Asamblea }}$ Mundial de la Salud. Función y responsabilidades de la OMS en las investigaciones sanitarias. Proyecto de estrategia de la OMS sobre investigaciones en pro de la salud. Informe de la Secretaría; 2010. Fecha de consulta: 12 de octubre de 2018. Disponible en: http://apps.who.int/gb/ebwha/pdf_files/ wha63/a63_22-sp.pdf.

2. Bunge M. La investigación científica. Su estrategia y su filosofía. Barcelona: Editorial Ariel; 1983. P 19

3. Bunge M. La ciencia, su método y su filosofía. Buenos Aires: Siglo XX; 1988.P 7-40

\section{(ㅇ) $(1)(8$}

Esta obra está bajo una licencia de Creative Commons Reconocimiento-NoComercial 4.0 Internacional 


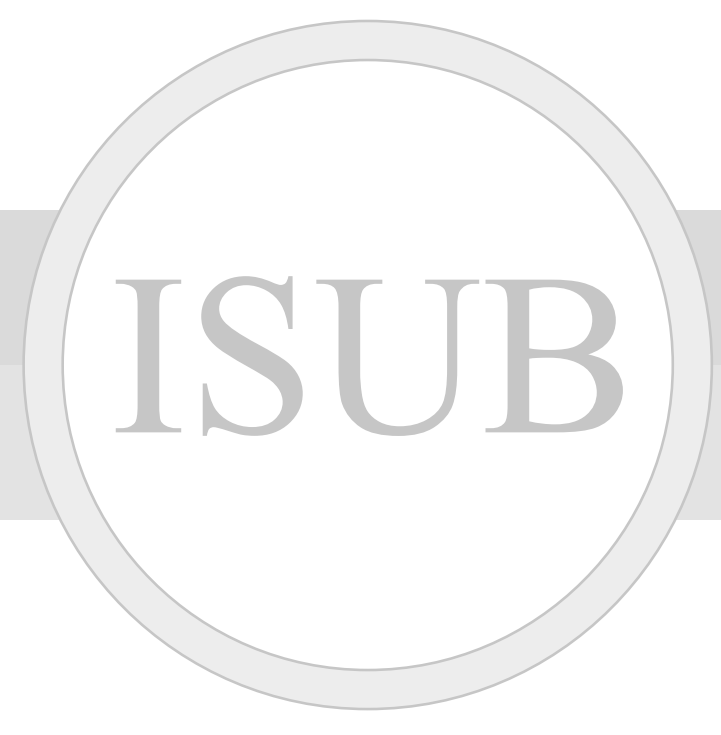

